\section{Uveal melanoma: relatively rare but deadly cancer}

S Kaliki ${ }^{1}$ and CL Shields ${ }^{2}$

\begin{abstract}
Although it is a relatively rare disease, primarily found in the Caucasian population, uveal melanoma is the most common primary intraocular tumor in adults with a mean age-adjusted incidence of 5.1 cases per million per year. Tumors are located either in iris $(4 \%)$, ciliary body $(6 \%)$, or choroid $(90 \%)$. The host susceptibility factors for uveal melanoma include fair skin, light eye color, inability to tan, ocular or oculodermal melanocytosis, cutaneous or iris or choroidal nevus, and BRCA1-associated protein 1 mutation. Currently, the most widely used firstline treatment options for this malignancy are resection, radiation therapy, and enucleation. There are two main types of radiation therapy: plaque brachytherapy (iodine-125, ruthenium106 , or palladium-103, or cobalt-60) and teletherapy (proton beam, helium ion, or stereotactic radiosurgery using cyber knife, gamma knife, or linear accelerator). The alternative to radiation is enucleation. Although these therapies achieve satisfactory local disease control, long-term survival rate for patients with uveal melanoma remains guarded, with risk for liver metastasis. There have been advances in early diagnosis over the past few years, and with the hope survival rates could improve as smaller tumors are treated. As in many other cancer indications, both early detection and early treatment could be critical for a positive long-term survival outcome in uveal melanoma. These observations call attention to an unmet medical need for the early treatment of small melanocytic lesions or small melanomas in the eye to achieve local disease control and vision preservation with the possibility to prevent metastases and improve overall patient survival.

Eye (2017) 31, 241-257; doi:10.1038/eye.2016.275; published online 2 December 2016
\end{abstract}

\section{Introduction}

Melanoma is a relatively rare tumor arising from melanocytes located at various anatomic locations, including skin, mucous membrane (nasal mucosa, oropharyngeal, pulmonary, gastrointestinal, vaginal, anal/rectal, urinary tract), ocular region (uvea, conjunctiva, eyelid, orbit), and rarely from unknown primary sites. ${ }^{1}$ In a review of 84836 cases from the National Cancer Database, including cases diagnosed between 1985 and 1994, the percentages of melanomas arising from the skin, eye and adnexa, mucosa, and unknown primaries were $91 \%, 5 \%, 1 \%$, and $2 \%$, respectively. ${ }^{1}$

Among ocular melanomas, $83 \%$ arise from uvea, $5 \%$ from conjunctiva, and $10 \%$ from other sites. ${ }^{1}$ The most common site for uveal melanoma is the choroid. In a study of 8033 patients with uveal melanoma by Shields et al, ${ }^{2}$ the tumor was located in the iris in $285(4 \%)$, ciliary body in $492(6 \%)$, and choroid in 7256 $(90 \%)$ cases. In this report, we discuss the epidemiology, diagnosis, treatment, and prognosis of uveal (iris, ciliary body, and choroidal) melanoma. We also discuss the importance of early detection and potential new treatments.

\section{Incidence of uveal melanoma}

Analysis of the Surveillance, Epidemiology, and End Results (SEER) program database of the United States National Cancer Institute over a 36-year period between 1973 and 2008, including 4070 patients with primary uveal melanoma, revealed an overall mean age-adjusted incidence of uveal melanoma at 5.1 cases per million per year. ${ }^{3}$ Similarly, analysis of data from the European Cancer Registry-based study on survival and care of cancer patients

(EUROCARE) in Europe, including 6673 patients with uveal melanoma diagnosed from 1983 to 1994, revealed standardized incidence rates of 1.3-8.6 cases per million per year. ${ }^{4}$ In Europe, the incidence of uveal melanoma followed a north-to-south decreasing gradient from a minimum of 2 per million per year in Spain and southern Italy to a maximum of 8 per million per
${ }^{1}$ The Operation Eyesight Universal Institute for Eye Cancer, LV Prasad Eye Institute, Hyderabad, India

${ }^{2}$ Ocular Oncology Service, Wills Eye Hospital, Thomas Jefferson University, Philadelphia, PA, USA

Correspondence: S Kaliki, The Operation Eyesight Universal Institute for Eye Cancer, LV Prasad Eye Institute, Road No. 2, Banjara Hills, Hyderabad 500034, India

Tel: +91 4030612502 ;

Fax: +914023548339. E-mail: kalikiswathi@yahoo. com

Received: 4 September 2016 Accepted in revised form:

1 November 2016

Published online:

2 December 2016 
year in Norway and Denmark. ${ }^{4}$ This north-to-south decreasing gradient is related to the protective effect of ocular pigmentation in the southern populations with respect to higher exposure to ultraviolet light at lower latitudes. ${ }^{4}$ The incidence of uveal melanoma is low in Africa and Asia, with an incidence rate of $0.2-0.3$ cases per million per year. ${ }^{5}$ Across continents, there has been no significant change in the overall incidence of uveal melanoma over the years..$^{3,4,6,7}$ Based on region of origin, the number of uveal melanoma cases per year has been estimated per population at 316 for Africans, 857 for Asians, 1154 for Hispanics, and 4351 for White nonHispanics. ${ }^{5}$

The next sections include discussions of the various characteristics studied in diagnosis of uveal melanoma: age, gender, and race, followed by a discussion of the factors that increase the likelihood of developing uveal melanoma.

\section{Age}

Uveal melanoma is more commonly seen in older age groups, with a progressively rising age-specific incidence rate that peaks at age 70 years, and plateaus after 75 years. ${ }^{3,4,8,9}$ Uveal melanoma in children is rare, and congenital uveal melanoma is extremely rare. ${ }^{9-11}$ In a study of uveal melanoma in children and teenagers, age at presentation was 0 to 5 years in 3\%, 5.1 to 10 years in $11 \%, 10.1$ to 15 years in $35 \%$, and 15.1 to $\leq 20$ in $50 \% .{ }^{10}$ The age-specific incidences of uveal melanoma per million population ${ }^{9}$ are listed in Table 1.

In the United States and Europe where there is a prominent Caucasian population, the median age of uveal melanoma diagnosis is 59 to 62 years. ${ }^{2,3,8}$ In a recent study of epidemiological trends in uveal melanoma in 7043 patients from the SEER database over 1973 to 2009, the mean age at diagnosis increased between 1973 (59 years) and 2009 (62 years). ${ }^{8}$ This increasing trend was speculated to be related to increasing life expectancy and frequent

Table 1 Age-specific incidences of uveal melanoma per million population in the United States

\begin{tabular}{lcc}
\hline Age (years) & Males & Females \\
\hline $0-4$ & 0 & 0 \\
$10-14$ & 0.2 & 0 \\
$20-24$ & 0.4 & 0.6 \\
$30-34$ & 1.7 & 1.7 \\
$40-44$ & 3.9 & 2.4 \\
$50-54$ & 10.5 & 6.5 \\
$60-64$ & 14.9 & 11.7 \\
$70-74$ & 24.5 & 17.8 \\
$80-84$ & 23.2 & 16.1 \\
\hline
\end{tabular}

Adapted from Singh and Topham. ${ }^{9}$ ocular examinations. ${ }^{8}$ However, studies from Asian countries indicate lower age at diagnosis, with mean age of 45 years in Chinese populations, 46 years in Asian Indians, 51 years in Taiwanese, 54 years in Korean, and 55 years in Japanese populations. ${ }^{5,6,12-15}$ Similarly, lower age at presentation has been reported in Hispanics at 52 years and in Blacks at 54 years. ${ }^{16,17}$

\section{Gender}

In population-based epidemiological studies, the ageadjusted incidence of uveal melanoma is higher in males compared with females. ${ }^{3,4}$ In an analysis of SEER data, the age-adjusted incidence of uveal melanoma was 5.8 per million in males compared with 4.4 per million in females. ${ }^{3}$ In a study including Australian populations, the age-standardized incidence in men was higher $(0.83$ per $100000)$ compared with that in women $(0.59$ per 100000$)$ for choroidal melanomas. ${ }^{18}$ The difference in incidence between the genders was largely due to significantly higher rates in men 65 years and older. However, there was no significant difference in rates between men and women younger than 65 years. ${ }^{18}$ Gender differences in rates in large cohort clinical studies with no age adjustments have not been reported. In fact, a large study of 8033 consecutive patients with uveal melanoma showed that $50 \%$ were males and $50 \%$ were females. $^{2}$

\section{Race}

Uveal melanoma is more common in the White population. The ratio of uveal melanoma in Black: White patients is estimated at $1: 15$ to $1: 50 .{ }^{19-21}$ The relative risk (RR) calculation of uveal melanoma in various racial groups (Black, Asian and Pacific Islander, Hispanic, and non-Hispanic White) in 1352 patients using 1992 to 2000 SEER program data revealed the ratios of Black:Asian: Hispanic:non-Hispanic White at $1: 1.2: 5: 19 .^{21}$ The Black: White ratio is influenced by gender at $1: 42$ in male patients and $1: 12$ in female patients, with a greater incidence in males $v s$ females $(3.5: 1) .{ }^{21}$ In a comprehensive analysis of 8100 consecutive patients with uveal melanoma, the patient race was Caucasian (98\%), Hispanic (1\%), Asian ( $<1 \%)$, and African American $(<1 \%) .{ }^{19}$ Margo et al ${ }^{20}$ reported that the RR of uveal melanoma for Blacks compared with non-Hispanic Whites was 0.03 . The rarity of uveal melanoma in Blacks is probably related to protective effects associated with dark skin pigmentation or unknown culturalenvironmental factors. 


\section{Predisposing factors}

\section{Host susceptibility factors}

Skin color, hair color, and ability to tan The host susceptibility factors for uveal melanoma include fair skin, blond hair, light eye color, and inability to tan. Weis et $a l^{22}$ provided a meta-analysis studying the association between host susceptibility factors and uveal melanoma revealed the following factors to be statistically significant: light eye color (RR, 1.75), fair skin color (RR, $1.80)$, and inability to tan (RR, 1.64). Blond hair was not a statistically significant independent risk factor. ${ }^{22}$ The increased occurrence of uveal melanoma in lighterskinned people and those with light (blue or grey) colored eyes may be related to less melanin being present in the choroid and retinal pigment epithelium, which results in less protection from ultraviolet light, and increased risk of developing uveal melanoma. ${ }^{22}$ Uveal melanoma is more common in people who sunburn easily compared with those who tan well, and as with the previous factors, is likely related to light skin color and less melanin in the eye. $^{22}$

Oculodermal melanocytosis Oculodermal melanocytosis represents a congenital pigmentary abnormality with slate-grey pigmentation of the periocular skin, sclera, uvea, orbit, meninges, palate, and tympanic membrane and is an important risk factor for development of uveal melanoma. ${ }^{23-25}$ This condition is generally mostly unilateral, and in some cases, the pigmentation is limited only to the eye. Ocular (no eyelid involvement)/ oculodermal melanocytosis is 35 times more common in patients with uveal melanoma, and occurs in $0.04 \%$ of the White population and $\sim 1.4$ to $3 \%$ of those with uveal melanoma. ${ }^{23,25}$ The estimate of lifetime risk for a Caucasian patient with ocular/oculodermal melanocytosis to develop uveal melanoma is 1 in $400 .{ }^{24}$

Cutaneous, iris, and choroidal nevus An association between uveal melanoma and atypical cutaneous nevi (dysplastic nevi), common cutaneous nevi, and cutaneous freckles has been established. Patients with atypical cutaneous nevi are 4.36 to 10.4 times more likely to develop ocular melanoma than the average population. ${ }^{26,27}$

Iris nevus is a risk factor for uveal melanoma in general and it is a particular risk for iris melanoma, although the rate of transformation of iris nevus into melanoma is not clearly understood. ${ }^{28}$ In a study of 175 patients with suspicious iris nevus by Territo et al, ${ }^{29} 8$ (5\%) lesions showed clinical evidence of growth into iris melanoma at a mean follow-up of 5 years. In a recent study of 1611 patients with iris nevus, only $2 \%$ of patients showed transformation of nevus to melanoma. ${ }^{30}$ By multivariable analysis, the features predictive of growth included age $<40$ years, hyphema, inferior tumor location, diffuse flat tumor configuration, ectropion uveae, and feathery, geographic margins. For early detection of iris melanoma, these important predictive factors can be remembered by the mnemonic ABCDEF representing A-age young, $\mathrm{B}$ blood (hyphema), C-clock hour inferiorly, D-diffuse,

E-ectropion, and F-feathery margins (Table 2). ${ }^{30}$

Choroidal nevus is a common intraocular lesion, found in $\sim 5 \%$ of Caucasians in the United States, according to the National Health and Nutrition Examination Survey. ${ }^{31}$ Choroidal nevus is found to be associated with cardiovascular, renal, autoimmune, and occupational risk factors, female reproductive factors, and obesity. ${ }^{31-33}$ The estimated annual rate of malignant transformation of a choroidal nevus, based on the premise that all melanomas arise from nevus is mathematically calculated at 1 in $8845 . .^{34}$ The annual rate of malignant transformation of choroidal nevus gradually increases with age, with the lowest rate of 1 in 269565 for the youngest age group (15-19 years) and the highest rate of 1 in 3664 for the oldest age group (80-84 years). ${ }^{34}$ Risk factors predictive of transformation of choroidal nevus into melanoma include: tumor thickness $>2 \mathrm{~mm}$, subretinal fluid, symptoms, orange pigment, margin near disc, ultrasonographic hollowness, and absence of halo or

Table 2 Risk factors for the growth of iris nevus into melanoma

\begin{tabular}{llccc}
\hline Initial & Feature & $\begin{array}{c}\text { Hazard } \\
\text { ratio }\end{array}$ & $\begin{array}{c}\text { \% of patients with tumor growth having this } \\
\text { feature }\end{array}$ & $\begin{array}{c}\text { \% of patients with no tumor growth having this } \\
\text { feature }\end{array}$ \\
\hline A & Age $\leq 40$ years & 3 & 48 & 24 \\
B & Blood & 9 & 11 & $<1$ \\
C & Clock hour-inferior & 9 & 96 & 71 \\
D & Diffuse & 14 & 4 & $<1$ \\
& configuration & & 48 & 18 \\
E & Ectropion uveae & 4 & 52 & 24 \\
F & Feathery margin & 3 & & \\
\hline
\end{tabular}

Adapted from Shields et al. ${ }^{30}$ 
drusen. ${ }^{35,36}$ Shields et al, ${ }^{35,36}$ developed a mnemonic (TFSOM UHHD) to help practitioners remember the ocular melanoma risk factors. TFSOM UHHD stands for 'To Find Small Ocular Melanoma Using Helpful Hints Daily', representing Thickness, Fluid, Symptoms, Orange pigment, Margin, Ultrasonographic Hollowness, Halo absence, and Drusen absence (Table 3). At 5 years, tumors that display one factor show growth in $38 \%$ of cases, and those with two or more factors show growth in over $50 \%$ of cases. ${ }^{35,36}$

BAP1 mutation BAP1 (BRCA1-associated protein 1) is a nuclear protein encoded by the tumor suppressor gene located on chromosome 3p21.1. The BAP1 tumor predisposition syndrome is a recently identified hereditary cancer syndrome. The somatic or germline mutation of BAP1 predisposes patients to develop uveal melanoma, malignant mesothelioma, cutaneous melanomas, basal cell carcinoma, and renal cell carcinoma. ${ }^{37}$ This mutation is transmitted in a Mendelian manner with $50 \%$ of the offspring inheriting the mutation. The malignancies occurring in patients with germline BAP1 mutations are less aggressive compared with patients with the same types of tumors that do not show this mutation. ${ }^{37}$ A review of 507 blood samples of patients with uveal melanoma disclosed 25 (5\%) with BAP1 polymorphisms, and are associated with larger tumors and higher rates of ciliary body involvement. ${ }^{38}$

\section{Environmental factors}

Sunlight exposure Various studies have explored the particular association between ultraviolet light exposure and occurrence of uveal melanoma. ${ }^{39,40}$ However, published literature does not unequivocally implicate sunlight exposure as a risk factor for uveal melanoma. 39,40 Some studies suggest that chronic ultraviolet light exposure is an independent risk factor for uveal melanoma, whereas other studies contradict this. ${ }^{39,40}$ Shah et $a l^{39}$ provided a meta-analysis of all published reports and demonstrated that chronic ultraviolet light exposure, occupational sunlight exposure, outdoor leisure sunlight exposure, and geographic latitude of birth played minimally significant roles in the development of uveal melanoma. A study from Germany revealed that people with light iris color have increased risk for melanoma if they were exposed to ultraviolet radiation. ${ }^{40}$

\section{Intermittent exposure to artificial ultraviolet light No} consistent evidence indicates occupational ultraviolet light exposure as an independent risk factor for uveal melanoma. However, some studies suggest that it is a significant risk factor for arc welders who have an occupational exposure to artificial ultraviolet light. ${ }^{41,42}$ Increasing evidence suggests that blue light exposure, as opposed to ultraviolet light exposure, may influence the oncogenesis and progression of uveal melanoma. ${ }^{43}$ In a meta-analysis of five case-control studies, it was shown that occupational cooking was associated with increased risk of uveal melanoma in both men and women. ${ }^{44}$

We now discuss uveal melanomas based on anatomical location (iris, ciliary body, or choroid) and the particular clinical features and risk factors.

\section{Iris melanoma}

\section{Clinical features}

Iris melanoma can be circumscribed $(90 \%)$ or diffuse $(10 \%) .{ }^{45,46}$ Iris melanoma, although much less common, is usually diagnosed 10-20 years earlier than ciliary body or choroidal melanomas. ${ }^{2,45,46}$ In most cases, it is an incidental finding due to iris color changes (heterochromia) and pupil distortion (corectopia). Iris melanoma is most commonly located in the inferior quadrant $(45 \%)$ and causes corectopia (45\%), secondary

Table 3 Risk factors for the growth of choroidal nevus into melanoma

\begin{tabular}{|c|c|c|c|c|c|}
\hline Initial & Mnemonic & Feature & $\begin{array}{l}\text { Hazard } \\
\text { ratio }\end{array}$ & $\begin{array}{c}\% \text { of patients with tumor growth having } \\
\text { this feature }\end{array}$ & $\begin{array}{c}\% \text { of patients with no tumor growth having } \\
\text { this feature }\end{array}$ \\
\hline $\mathrm{T}$ & To & Thickness $>2 \mathrm{~mm}$ & 2 & 46 & 15 \\
\hline $\mathrm{F}$ & Find & Fluid & 3 & 39 & 8 \\
\hline S & Small & Symptoms & 2 & 38 & 10 \\
\hline $\mathrm{O}$ & Ocular & Orange pigment & 3 & 32 & 6 \\
\hline M & Melanoma & Margin $\leq 3 \mathrm{~mm}$ to disc & 2 & 58 & 31 \\
\hline $\mathrm{UH}$ & $\begin{array}{l}\text { Using } \\
\text { helpful }\end{array}$ & $\begin{array}{l}\text { Ultrasonographic } \\
\text { hollowness }\end{array}$ & 3 & 57 & 15 \\
\hline $\mathrm{H}$ & Hints & Halo absence & 6 & 98 & 95 \\
\hline $\mathrm{D}$ & Daily & Drusen absence & $<1$ & 49 & NA \\
\hline
\end{tabular}

Abbreviation: NA, not available.

Adapted from Shields et $a l^{36}$ and Collaborative Ocular Melanoma Study Group. ${ }^{101}$ 
glaucoma $(35 \%)$, angle seeding $(28 \%)$, ectropion uveae (24\%), hyphema (3\%), and extraocular extension $(3 \%) .{ }^{47}$ Secondary glaucoma occurs because of direct compression of the anterior chamber angle, or tumor invasion of the angle, or accumulation of tumor cells or pigment or pigment-laden macrophages in the trabecular meshwork causing outflow obstruction. ${ }^{48}$

Diffuse iris melanoma has an infiltrative, flat, illdefined growth pattern with confluent or multifocal iris involvement. The diagnosis of diffuse iris melanoma is challenging and is often delayed. The classic findings of diffuse iris melanoma include acquired hyperchromic heterochromia iridis and ipsilateral glaucoma. ${ }^{49}$

Ring melanoma of the anterior chamber is a distinct rare variant that manifests as circumferential, flat tumor growth confined to the trabecular meshwork and anterior chamber angle structures. It presents as refractory unilateral glaucoma simulating pigmentary glaucoma and can be diagnosed only by gonioscopy and UBM. ${ }^{50}$

\section{Diagnosis}

The American Joint Committee on Cancer Classification (AJCC) has classified iris melanoma based on tumor location, tumor size in clock hours, tumor extension to ciliary body, and/or choroid and associated features of secondary glaucoma and extraocular extension ${ }^{51}$ (see Table 4).

The diagnosis of iris melanoma is carried out by clinical examination with slit-lamp biomicroscopy. Gonioscopy is a useful adjunct to assess the involvement of the anterior chamber angle. For small tumors, anterior segment optical coherence tomography (AS-OCT) is useful with high-resolution imaging of anterior and lateral surfaces. For large iris melanomas, ultrasound biomicroscopy
(UBM) and AS-OCT assist in visualization of the posterior tumor extent. B-scan ultrasonography (USG) is superior to AS-OCT in assessing large pigmented lesions because sound waves penetrate better than light energy. ${ }^{52}$ Transillumination also aids in assessing ciliary body involvement. Occasionally, fine-needle aspiration biopsy may be used to confirm diagnosis, especially for small iris melanomas. In an analysis of 100 consecutive biopsies of iris lesions, Shields et al ${ }^{53}$ showed that adequate sample could be obtained in $99 \%$ cases with minimal complications.

The most common differential diagnoses for circumscribed iris melanoma are iris nevus, ocular melanocytosis, leiomyoma, iris metastasis, iris cyst, and inflammatory conditions such as sarcoidosis and juvenile xanthogranuloma. ${ }^{46}$ Diffuse iris melanomas must be differentiated from congenital heterochromia, congenital ectropion iridis, diffuse iris nevus, pigmentary glaucoma, melanocytomalytic glaucoma, ocular siderosis, hemosiderosis, and iridocorneal endothelial syndrome. ${ }^{49}$

\section{Treatment}

Small iris nevus/melanomas ( $<3 \mathrm{~mm}$ basal diameter) in an asymptomatic patient can be monitored for growth with periodic photographic documentation. Small iris melanoma with documented growth is managed by partial iridectomy (removal of portion of iris), iridotrabeculectomy (removal of a portion of the iris and trabecular meshwork needed if the tumor invades the anterior chamber angle), or iridocyclectomy (removal of a portion of the iris and ciliary body indicated in tumors with ciliary body extension). ${ }^{45,46}$ Plaque radiotherapy and proton beam radiotherapy are beneficial for tumors with

Table 4 Iris melanoma based on American Joint Cancer Committee (AJCC 7th edition) classification ${ }^{\text {a }}$

\begin{tabular}{ll}
\hline Primary tumor $(T)$ & \\
\hline T1 & Tumor limited to the iris \\
T1a & Tumor limited to the iris $\leq 3$ clock hours \\
T1b & Tumor limited to the iris $\geq 3$ clock hours \\
T1c & Tumor limited to the iris with secondary glaucoma \\
T2 & Tumor extending into the ciliary body, choroid, or both \\
T2a & Tumor extending into the ciliary body, choroid, or both, with secondary glaucoma \\
T3 & Tumor extending into the ciliary body, choroid, or both, with scleral extension \\
T3a & Tumor extending into the ciliary body, choroid, or both, with scleral extension and secondary glaucoma \\
T4 & Tumor with extrascleral extension \\
T4a & Tumor with extrascleral extension $\leq 5 \mathrm{~mm}$ in diameter \\
T4b & Tumor with extrascleral extension $\geq 5$ mm in diameter \\
\hline
\end{tabular}

a'Source: Edge et al. ${ }^{51}$ 


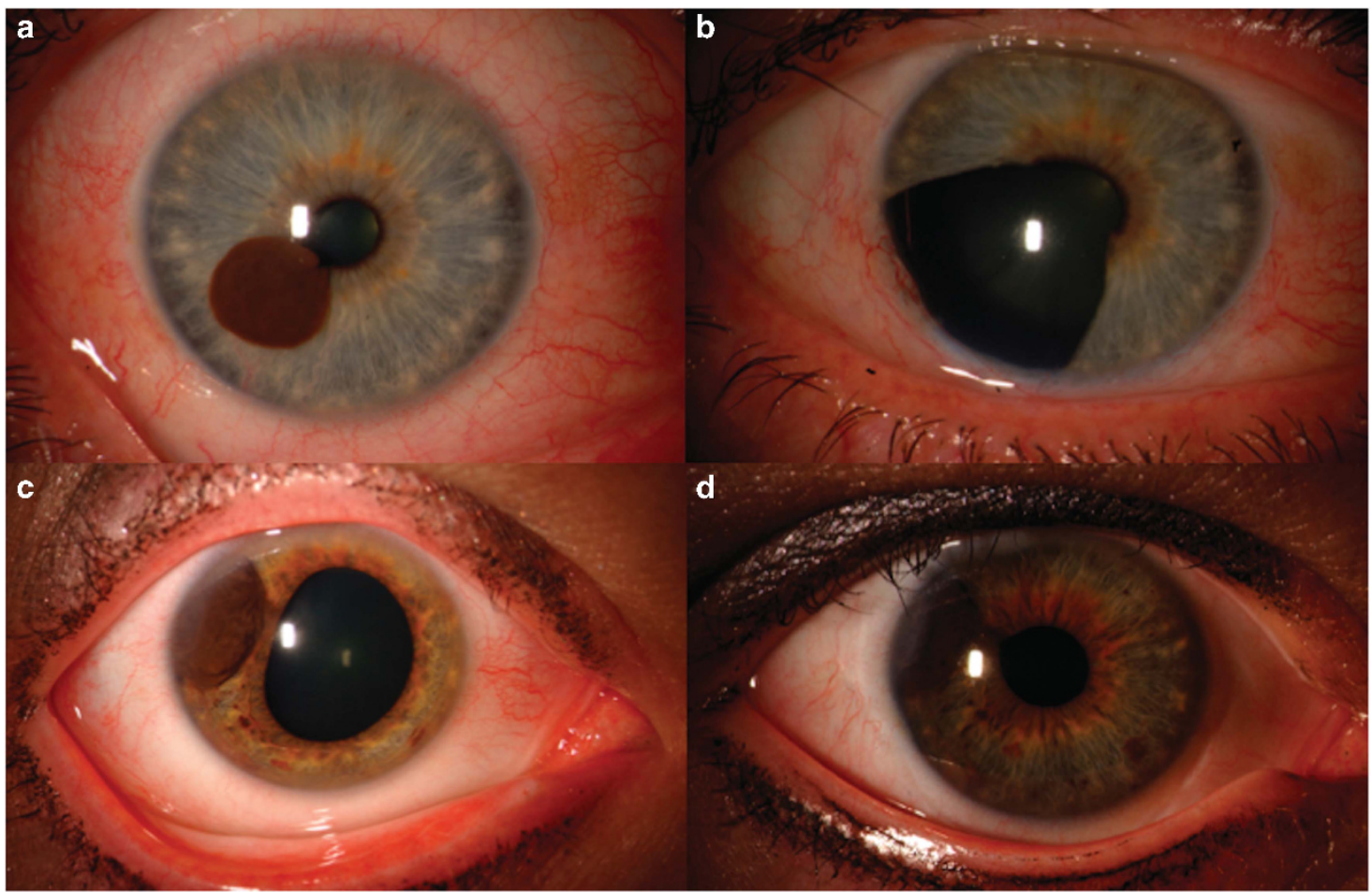

Figure 1 Iris melanoma. (a) Iris melanoma in the mid-zone of iris (b) treated by iridectomy. (c) Iris melanoma at the root of iris and (d) treated with iodine-125 plaque radiotherapy.

extensive tumor seeding and in non-resectable iris tumors, achieving melanoma control in $92 \%$ of cases. ${ }^{49,54,55}$ (Figure 1). However, vision loss is a worrisome adverse effect of this treatment. Enucleation is indicated for eyes with large tumor, diffuse iris melanoma, eyes with poor initial visual acuity, and those with recurrent tumor.

\section{Prognosis}

The prognosis of iris melanoma is better than the prognosis of ciliary body and choroidal melanoma, with five to ten times lower mortality rates. $2,47,56$ This may be related to younger age at presentation, smaller tumor size, and less biologic activity. ${ }^{56}$ In a review of 317 patients with iris melanoma, metastasis occurred in $4 \%$ of patients, and $2 \%$ of patients died because of metastasis during a mean follow-up period of 53 months. ${ }^{47}$ Kaplan-Meier estimates of metastasis and death at 10 years were $9 \%$ and $3 \%$, respectively. ${ }^{47}$ The prognostic factors for a worse outcome included increasing age at diagnosis, secondary glaucoma, increased tumor thickness, posterior tumor margin at iris root or anterior chamber angle, and extraocular tumor extension. ${ }^{2,47,57}$

\section{Ciliary body melanoma and choroidal melanoma}

The symptoms of ciliary body and choroidal melanoma include blurred vision (38\%), photopsia $(9 \%)$, floaters $(7 \%)$, visual field loss $(6 \%)$, visible tumor $(3 \%)$, pain $(2 \%)$, metamorphopsia $(2 \%)$, and $30 \%$ of patients are asymptomatic. ${ }^{58}$ Ciliary body melanoma is often diagnosed late as the lesion remains hidden behind the iris, and the patient seldom has any clinical symptoms until the lesion is large. Consequently, when the tumors are eventually diagnosed, they present as fairly large with a mean basal diameter of $11.7 \mathrm{~mm}$ and tumor thickness of $6.6 \mathrm{~mm} .2$ Ring melanoma of the ciliary body is a rare distinct entity $(0.3 \%$ of all uveal melanomas) in which the tumor extends circumferentially involving the entire ciliary body, often without any nodular component. ${ }^{59}$

Choroidal melanoma presents as a dome-shaped mass $(75 \%)$ or has a mushroom configuration because of rupture of Bruch's membrane (19\%), and rarely presents as a diffuse variant $(6 \%)$. The lesion can be pigmented $(55 \%)$, nonpigmented $(15 \%)$, or has a mixed color $(30 \%)$, associated with retinal detachment $(71 \%)$, intraocular hemorrhage $(10 \%)$, or extraocular extension $(3 \%){ }^{2}$ In a review of 7256 cases of choroidal melanoma, the mean basal diameter was $11.3 \mathrm{~mm}$ and mean tumor thickness was $5.5 \mathrm{~mm}^{2}$ 


\section{Diagnosis}

The AJCC classifies ciliochoroidal melanoma based on tumor basal dimension, tumor thickness, ciliary body involvement, and associated extraocular extension ${ }^{51}$ (Table 5). Diagnosing small ciliary body melanoma is challenging as the melanoma location impedes the ability to visualize it directly. Most cases are detected when the tumors are large with iris or choroidal invasion.

Gonioscopy can detect involvement of the anterior chamber angle. Fundus examination with good indentation can help visualize some ciliary body melanomas. Shadowing on transillumination is detected in larger lesions. Conventional USG is a useful adjunct for larger tumors. Recently, high-frequency UBM is recognized as a valuable tool in the detection and followup of small ciliary body melanomas $(<4 \mathrm{~mm})$, which other conventional techniques would otherwise not detect. $^{52}$

The mainstay of diagnosis of choroidal melanoma is a detailed fundus evaluation with indirect ophthalmoscopy. Serial fundus photography helps monitor these lesions. Small choroidal melanomas can be detected by enhanced depth imaging optical coherence tomography (EDI-OCT), which is particularly useful in lesions $<3 \mathrm{~mm}$ in greatest dimension, and might be missed using routine diagnostic methods. ${ }^{60}$ Small choroidal melanomas are seen as dome-shaped lesions with smooth surface tomography, shaggy photoreceptors, and subretinal lipofuscin deposits and shallow subretinal fluid. ${ }^{60}$ EDI-OCT is also a useful tool for differentiating choroidal nevus from small choroidal melanoma; however, it has limited use in diagnosing tumors with thickness $>3 \mathrm{~mm}$. It also has limited use with heavily pigmented tumors, which cast a significant posterior shadow.

USG is an important diagnostic tool used to define tumor extent and shape, and to measure tumor dimensions of ciliary body/choroidal melanoma. Typical features of a posterior uveal melanoma on USG include acoustic hollowing, choroidal excavation (42\% to $65 \%$ ), and orbital shadowing. ${ }^{61,62}$ Spontaneous vascular movement (69-70\%) may be noted in a highly vascularized tumor. Ossoinig ${ }^{62}$ described four cardinal acoustic hallmarks of malignant melanoma on A-scan including a regular internal structure with similar height of the inner tumor spikes or regular decrease in height (positive angle kappa sign), low to medium reflectivity, solid consistency with no after movement of tumor spikes, and echographic sign of vascularization with a fast, spontaneous, continuous, flickering vertical motion of single tumor spikes. Fluorescein angiography (FFA) and indocyanine green (ICG) angiography have limited use in choroidal melanoma. The characteristic features on FFA include gradually increasing fluorescence that starts

Table 5 Posterior uveal melanoma based on American Joint Cancer Committee (AJCC 7th edition) classification ${ }^{\mathrm{a}}$

\begin{tabular}{|c|c|c|c|}
\hline Primary tumor $(T)$ & Tumor dimensions (mm) & Ciliary body involvement & Extraocular extension \\
\hline T1 & \multirow{5}{*}{$\begin{array}{l}\text { Tumor base }<3-9 \mathrm{~mm} \text { with thickness } \leq 6 \mathrm{~mm} \\
\text { Tumor base } 9.1-12 \mathrm{~mm} \text { with thickness } \leq 3 \mathrm{~mm}\end{array}$} & Yes or no & Yes or no \\
\hline T1a & & No & No \\
\hline $\mathrm{T} 1 \mathrm{~b}$ & & Yes & No \\
\hline T1c & & No & Yes; $\leq 5 \mathrm{~mm}$ in diameter \\
\hline T1d & & Yes & Yes; $\leq 5 \mathrm{~mm}$ in diameter \\
\hline \multicolumn{2}{|l|}{$\mathrm{T} 2$} & Yes or no & Yes or no \\
\hline T2a & Tumor base $<9 \mathrm{~mm}$ with thickness $6-9 \mathrm{~mm}$ & No & No \\
\hline $\mathrm{T} 2 \mathrm{~b}$ & Tumor base $9.1-12 \mathrm{~mm}$ with thickness $3.1-9 \mathrm{~mm}$ & Yes & No \\
\hline $\mathrm{T} 2 \mathrm{c}$ & Tumor base $12.1-15 \mathrm{~mm}$ with thickness $\leq 6 \mathrm{~mm}$ & No & Yes; $\leq 5 \mathrm{~mm}$ in diameter \\
\hline $\mathrm{T} 2 \mathrm{~d}$ & Tumor base $15.1-18 \mathrm{~mm}$ with thickness $\leq 3 \mathrm{~mm}$ & Yes & Yes; $\leq 5 \mathrm{~mm}$ in diameter \\
\hline \multicolumn{2}{|l|}{ T3 } & Yes or no & Yes or no \\
\hline T3a & Tumor base $3.1-9 \mathrm{~mm}$ with thickness $9.1-12 \mathrm{~mm}$ & No & No \\
\hline T3b & Tumor base $9.1-12 \mathrm{~mm}$ with thickness $9.1-15 \mathrm{~mm}$ & Yes & No \\
\hline T3c & Tumor base $12.1-15 \mathrm{~mm}$ with thickness $6.1-15 \mathrm{~mm}$ & No & Yes; $\leq 5 \mathrm{~mm}$ in diameter \\
\hline T3d & Tumor base $15.1-18 \mathrm{~mm}$ with thickness $3.1-12 \mathrm{~mm}$ & Yes & Yes; $\leq 5 \mathrm{~mm}$ in diameter \\
\hline \multicolumn{2}{|l|}{$\mathrm{T} 4$} & Yes or no & Yes or no \\
\hline $\mathrm{T} 4 \mathrm{a}$ & Tumor base $12.1-15 \mathrm{~mm}$ with thickness $>15 \mathrm{~mm}$ & No & No \\
\hline $\mathrm{T} 4 \mathrm{~b}$ & Tumor base $15.1-18 \mathrm{~mm}$ with thickness $>12 \mathrm{~mm}$ & Yes & No \\
\hline $\mathrm{T} 4 \mathrm{c}$ & Tumor base $>18 \mathrm{~mm}$ with any thickness & No & Yes; $\leq 5 \mathrm{~mm}$ in diameter \\
\hline $\mathrm{T} 4 \mathrm{~d}$ & & Yes & Yes; $\leq 5 \mathrm{~mm}$ in diameter \\
\hline T4e & Any tumor size & Yes or no & Yes; $>5 \mathrm{~mm}$ in diameter \\
\hline
\end{tabular}

aSource: Edge et al. ${ }^{51}$ 
at or before the arterial phase, increases in intensity well into the recirculation phase, and persists for at least $45 \mathrm{~min}(86 \%){ }^{63}$ The tumors that have broken through Bruch's membrane characteristically reveal 'double circulation' pattern $(61 \%)$ because of superimposition of the intravascular fluorescence of the intact retinal vasculature over the fluorescence of large caliber vessels within choroidal tumor. ${ }^{64}$ ICG angiography allows better visualization of intrinsic vasculature in choroidal melanoma (66\%) with maximal fluorescence at an average of $18 \mathrm{~min}$ from injection and helps differentiate choroidal melanoma from choroidal hemangioma. ${ }^{65}$ With computed tomography, the posterior uveal melanoma is hyperdense with slight to moderate contrast enhancement. ${ }^{45}$ With magnetic resonance imaging, the lesion appears hyperintense on $\mathrm{T} 1$ and hypointense on T2-weighted image. ${ }^{45}$

\section{Differential diagnosis}

Differential diagnosis is an important consideration, because a variety of lesions can simulate posterior uveal melanoma. In a review of 12000 patients referred to an oncology practice as posterior uveal melanoma, 1739 (14\%) were found to have a simulating condition. ${ }^{66}$ The most common differential diagnoses include choroidal nevus ( $49 \%)$, peripheral exudative hemorrhagic chorioretinopathy $(8 \%)$, congenital hypertrophy of the retinal pigment epithelium (6\%), hemorrhagic detachment of the retina or pigment epithelium (5\%), circumscribed choroidal hemangioma (5\%), and age-related macular degeneration $(4 \%) .{ }^{66}$

\section{Treatment}

Following the previous discussion of the various types of melanoma, incidence and diagnosis, treatment is a crucial component for consideration. Management of posterior uveal melanoma depends on tumor location, tumor extent, tumor size, visual acuity on presentation, and systemic status. ${ }^{45}$ Treatment options include transpupillary thermotherapy (TTT) for small choroidal melanomas, photodynamic therapy (PDT) for small amelanotic choroidal melanomas, plaque radiotherapy and proton beam radiotherapy for small and medium ciliary body (Figure 2) or choroidal melanomas (Figure 3), enucleation for large posterior uveal melanomas with poor vision at presentation, and orbital exenteration for tumors with orbital tumor extension. ${ }^{45}$ For terminally ill patients with systemic metastasis, observation is preferred. Newer treatments on the horizon for the treatment of uveal melanoma include light-activated targeted therapy using viral-like nanoparticles administered by intravitreal injection for the early-stage treatment of primary uveal melanoma cells. This methodology is currently under scientific investigation. ${ }^{67}$ Different types of treatment are described below in more detail.

\section{Observation}

Treatment of small posterior uveal melanoma may include observation with watchful waiting. This means that the physician would carefully monitor a patient's condition but not give treatment unless symptoms appear or change. This may be an appropriate avenue for patients whose tumors are small and stable or growing slowly. The physician would carefully balance the risks of treatment against the possible benefits.

\section{Transpupillary thermotherapy}

TTT is a noninvasive treatment modality where infrared diode $810 \mathrm{~nm}$ laser light is delivered through a dilated pupil to the choroidal tumor surface. ${ }^{68}$ This increases tumor temperature to $45-60^{\circ}$ causing obliteration of tumor-related malformed blood vessels and consequent tumor necrosis. ${ }^{68}$ However, the depth of maximum penetration of TTT is $4 \mathrm{~mm}$, thus being useful only for small choroidal melanomas. ${ }^{68}$ The absorption of diode laser is best with more pigmented tumors.

The advantages of TTT include precise targeting of the laser, immediate tumor necrosis, ability to treat patients on an outpatient basis, and less damage to surrounding normal choroid compared with plaque radiotherapy. Complications include retinal traction $(44 \%)$, branch retinal vein occlusion $(26-41 \%)$, branch retinal artery occlusion (12\%), cystoid macular edema (9-23\%), macular epiretinal membrane $(23 \%)$, vitreous hemorrhage $(10 \%)$, retinal neovascularization $(6 \%)$, foveal traction $(4 \%)$, chorioretinal scar at fovea (4\%), tractional retinal detachment $(2 \%)$, optic disc atrophy $(2 \%)$, rhegmatogenous retinal detachment $(1 \%)$, and transient serous retinal detachment $(1 \%)$, optic disc edema $(<1 \%)$, and cataract $(<1 \%)$. 68,69

Tumor recurrence following TTT for choroidal melanoma is $9-28 \%$ of cases. ${ }^{68,69} \mathrm{~A}$ direct correlation is found between tumor recurrence and the number of risk factors predictive of tumor growth (TFSOM UHHD) ${ }^{69}$ The percentage recurrence at 10 years by Kaplan-Meier estimate was $18 \%$ with 1 or 2 risk factors, $35 \%$ with 3 to 5 risk factors, and $55 \%$ with $>6$ risk factors. ${ }^{69}$ Thus, TTT is less preferable in cases with multiple risk factors.

\section{Photodynamic thermotherapy}

PDT is a minimally invasive treatment modality. A photosensitizer is administered via intravenous injection, 


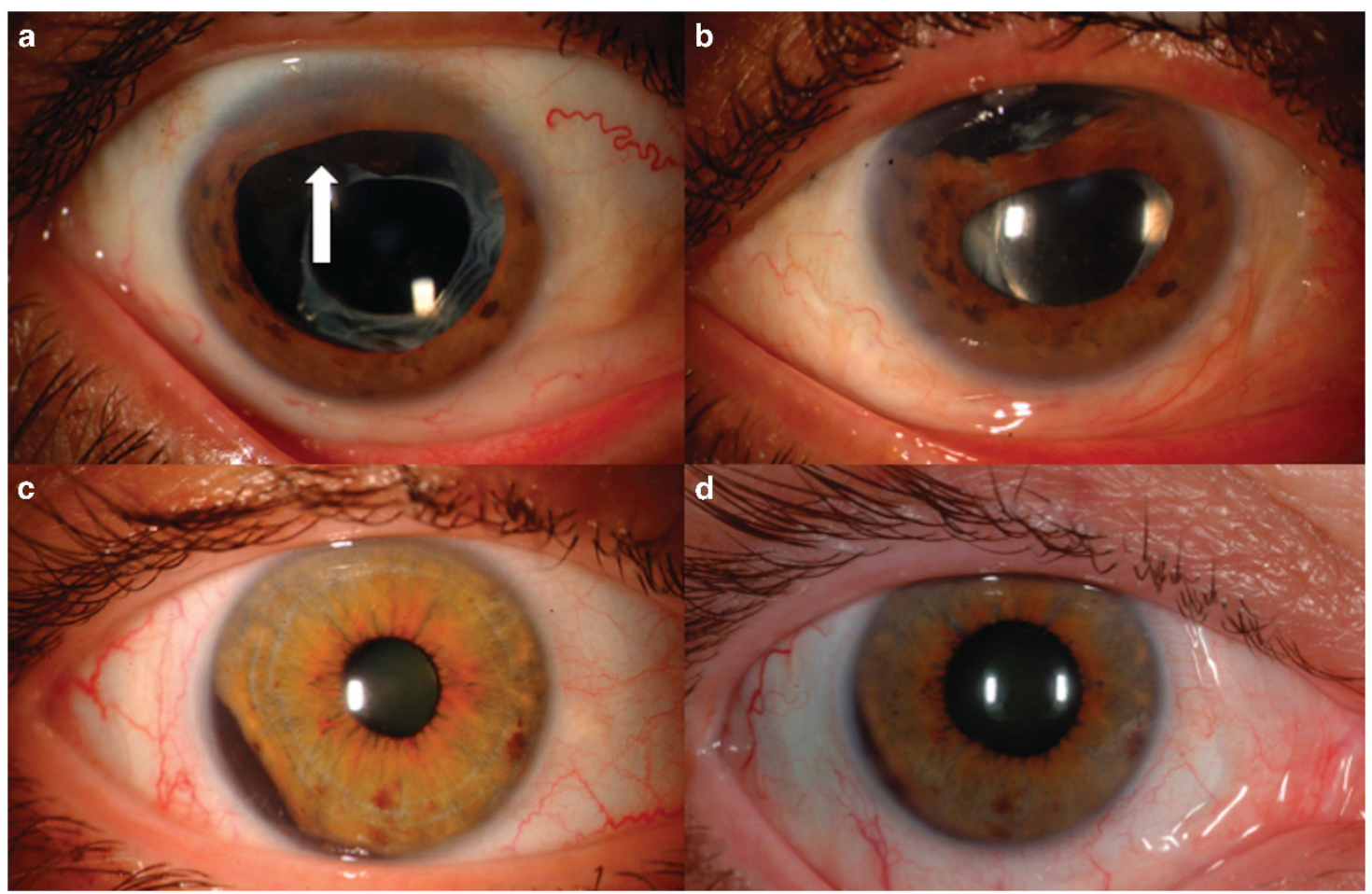

Figure 2 Ciliary body melanoma. (a) Ciliary body melanoma (white arrow) with minor extension into iris and (b) treated by partial lamellar scleroiridocyclectomy. (c) Ciliary body melanoma with extension into the iris root and (d) showed tumor control with iodine125 plaque radiotherapy.

which accumulates in tumor tissue and when activated with light at a specific wavelength causes tumor destruction by direct cytotoxic effect, causes destruction of peritumoral vasculature, and creates local inflammatory reaction resulting in increased autophagy. ${ }^{70}$ Verteporfin $6 \mathrm{mg} / \mathrm{m}^{2}$ is the most commonly used photosensitizer. Ten minutes after intravenous injection of verteporfin, $690 \mathrm{~nm}$ diode laser is delivered through a dilated pupil to the choroidal tumor surface. Standard PDT treatments begin after $15 \mathrm{~min}$ with $600 \mathrm{~mW} / \mathrm{cm}^{2}$ for $83 \mathrm{~s}$, which reaches a total energy of $50 \mathrm{~J} / \mathrm{cm}^{2}$. Some physicians use double fluence $\left(100 \mathrm{~J} / \mathrm{cm}^{2}\right)$ and double duration (166 s) of standard PDT. ${ }^{70}$

In a review of six reports with a total of 38 patients with choroidal melanoma in whom PDT with verteporfin was used as the primary treatment, tumor control was achieved in $80 \%$ cases and recurrence was noted in eight cases over 31 months. ${ }^{70}$ In a review of 64 patients in whom PDT with ICG was used as the primary treatment for choroidal melanoma, tumor regression was noted in $98 \%$ of cases. ${ }^{70}$ However, PDT is most beneficial in amelanotic melanomas with tumor thickness $<4 \mathrm{~mm} .{ }^{70}$ No serious complications have been reported with PDT.

\section{Radiotherapy}

Plaque radiotherapy with an apex dose of $80-100$ Gy is one of the most commonly used treatment modalities for posterior uveal melanoma. It is considered when the melanoma is $\leq 18 \mathrm{~mm}$ in diameter and $\leq 12 \mathrm{~mm}$ in thickness. Randomized, multicenter clinical trials conducted by the Collaborative Ocular Melanoma Study (COMS) group showed no difference in long-term survival rates of patients treated with plaque radiotherapy or enucleation in medium-sized tumors (basal diameter $<16 \mathrm{~mm}$ and apical height 2.5-10 mm). ${ }^{71}$ Another study showed that there was no mortality benefit with pre-enucleation radiotherapy for large tumors (basal diameter $\geq 16 \mathrm{~mm}$ and apical height $\geq 2 \mathrm{~mm}$ or any basal diameter with apical height $\geq 10 \mathrm{~mm}) .^{72}$

Iodine-125 is the most common radioisotope used to treat posterior uveal melanoma. Ruthenium-106 and Palladium-103 are also used. When plaque radiotherapy is combined with TTT, local tumor control rates are excellent with only $3 \%$ tumor recurrence. ${ }^{73}$ Ocular complications following iodine-125 plaque radiotherapy include radiation-induced dry eye in $8 \%$, diplopia in $10 \%$, strabismus in $2 \%$, keratitis in $4-21 \%$, 
iris neovascularization in 4-23\%, neovascular glaucoma in $2-45 \%$, cataract in $8-68 \%$, vitreous hemorrhage in $4-18 \%$, radiation retinopathy in
$10-63 \%$ radiation maculopathy in $13-52 \%$, optic neuropathy in $4-46 \%$, and scleral necrosis in $7-33 \% .{ }^{74,75}$

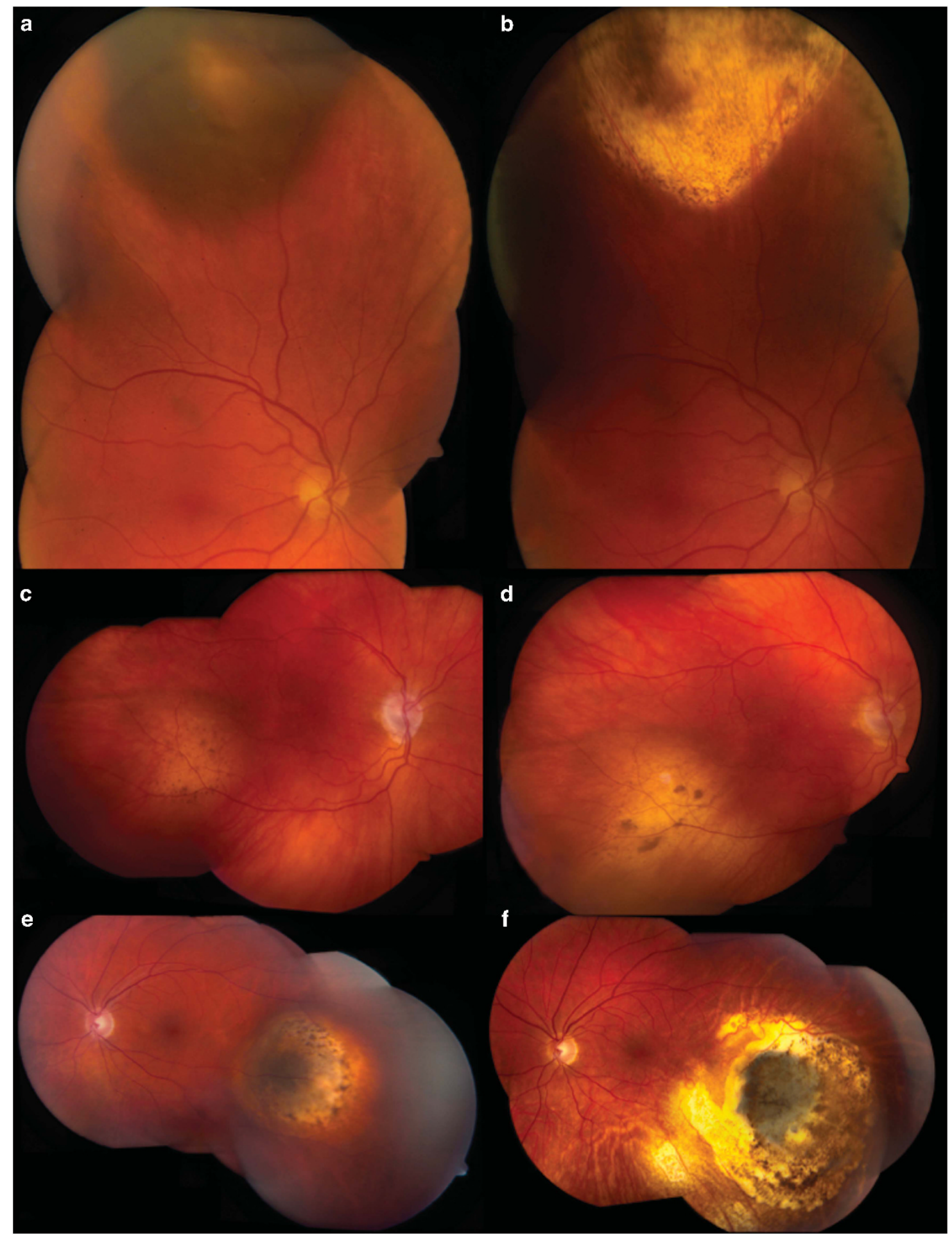

Figure 3 Management of choroidal melanoma. (a) Pigmented choroidal melanoma in the equatorial region of the right eye. (b) Flat scar following treatment with three sessions of TTT. (c) Amelanotic choroidal melanoma in the perifoveal region of the right eye and (d) completely regressed with two sessions of PDT. (e) Mixed pigmented-nonpigmented choroidal melanoma in the equatorial region of the left eye and (f) showed complete regression with iodine-125 plaque radiotherapy. 
Proton beam radiotherapy is another form of radiation treatment used for posterior uveal melanoma and is comparable to plaque radiotherapy for tumor control, visual outcome, and systemic prognosis. ${ }^{76}$ Stereotactic photon beam radiation therapy using cyber knife, gamma knife or linear accelerator can also used in the management of choroidal melanoma. The local tumor control, visual outcome, and survival of patients undergoing stereotactic photon beam radiation therapy are equivalent to those undergoing proton beam radiotherapy. ${ }^{77}$

\section{Local resection}

The tumor can be removed either by exoresection by en bloc tumor removal through a scleral opening or by endoresection in which the tumor is removed in a piecemeal manner with a vitreous cutter passed through the retina. In a review of 344 eyewall resections (exoresection) by Damato et al, ${ }^{78}$ the 8 -year actuarial rates of globe salvage, vision salvage of counting fingers or better, and local tumor control in eyes with no risk factors were $81 \%, 64 \%$, and $75 \%$, respectively. ${ }^{78}$ Endoresection of choroidal melanoma is controversial because of concerns about iatrogenic tumor dissemination. A study of the long-term outcome of primary endoresection of choroidal melanoma in 71 patients revealed high rates of local tumor control with tumor recurrence in 3\% patients at a median follow-up of 4 years. ${ }^{79}$ Some surgeons use primary proton beam radiotherapy before endoresection ${ }^{79}$ and some use adjunctive plaque radiotherapy after local resection of tumors. ${ }^{78}$

\section{Enucleation}

Enucleation is the second most commonly performed procedure for treating uveal melanoma. Tumors $>18 \mathrm{~mm}$ in basal diameter and $>12 \mathrm{~mm}$ in thickness, those with poor visual potential, and with moderate extraocular extension are advised enucleation. ${ }^{45,80}$ The Zimmerman hypothesis indicating that enucleation of eyes with uveal melanoma accelerates the dissemination of tumor cells has been reviewed and shown to be inaccurate. ${ }^{81}$

\section{Orbital exenteration}

Orbital exenteration is performed in eyes with large areas of extraocular extension or those with orbital tumor extension. Eyelid sparing techniques of orbital exenteration is used in these cases.

\section{Newer methods on the horizon}

There are no currently approved targeted therapies for the treatment of early-stage ocular melanoma. One treatment currently in preclinical development is light-activated AU-011, a novel virus like particle drug conjugate as a targeted therapy for the treatment of primary uveal melanoma. The drug is administered through intravitreal injection and activation by laser to produce targeted, rapid, tumor necrosis while sparing healthy ocular tissue. $^{82}$

Promoting tumor cell death and preserving healthy cells and tissues are the twin, often conflicting, goals of cancer treatments. The key value of the mechanism of action of AU-011 relies on the combined principles of targeted cancer therapy and multivalency. The viral particle component of AU-011 offers a multivalent tumor binding capacity over traditional bivalent antibody treatments. ${ }^{82}$ The targeted delivery makes tumor tissue more susceptible to the cytotoxic effect of the lightactivated dye component of the drug. Once the treated tumor is exposed to light at $689 \mathrm{~nm}$, excitation of the dye at the site of the tumor cell membrane leads to necrotic cell death without harming other ocular structures. ${ }^{83}$ Immunotherapy against uveal melanoma is also being studied with attempts to develop vaccine against uveal melanoma using autologous dendritic cells laden with tumor RNA. ${ }^{84}$

\section{Prognosis of posterior uveal melanoma}

Posterior uveal melanoma has a high tendency to metastasize and is associated with high mortality rates. The common sites of metastasis include liver (89\%), lung $(29 \%)$, bone $(17 \%)$, skin and subcutaneous tissue $(12 \%)$, and lymph node $(11 \%) .{ }^{85}$ In a study of long-term prognosis of patients with uveal melanoma who were observed for a median of 28 years, the Kaplan-Meier estimates of metastasis were $32 \%$ by 5 years, $50 \%$ by 15 years, $56 \%$ by 25 years, and $62 \%$ by 35 years. ${ }^{86}$ Of those patients who died of uveal melanoma, $90 \%$ died within 15 years and $98 \%$ died within 25 years. ${ }^{86}$ Metastasis and death beyond 25 years of diagnosis of posterior uveal melanoma is rare. The clinical, histopathologic, and cytogenetic features of uveal melanoma indicating poor prognosis with increased risk of developing metastasis ${ }^{87}$ are listed in Table 6.

\section{Clinical features predicting prognosis}

Although the influence of age on the prognosis of uveal melanoma is uncertain, recent studies indicate that a poor prognosis is more likely associated with increasing age. Lower metastatic rates in younger patients could be 
Table 6 Features predictive of poor prognosis for posterior uveal melanoma

\begin{tabular}{l}
\hline Clinical features \\
Older age at presentation \\
Male gender \\
Larger tumor basal diameter \\
Increased tumor thickness \\
Ciliary body tumor location \\
Diffuse tumor configuration \\
Association with ocular/oculodermal melanocytosis \\
Extraocular tumor extension at presentation \\
Advanced AJCC category and staging \\
Histopathologic features \\
Epithelioid cytology on histopathology \\
High mitotic activity/PC-10/Ki-67 \\
High values of mean diameter of 10 largest nucleoli \\
High microvascular density \\
Microvascular loops and patterns \\
Tumor-infiltrating lymphocytes \\
Tumor-infiltrating macrophages \\
High expression of insulin-like growth factor 1 receptor \\
High expression of HLA class I and II \\
Cytogenetic features \\
Chromosome 3-loss (monosomy 3) \\
Chromosome 8q-gain or 8p-loss \\
Chromosome 1p-loss \\
Chromosome 6q-loss \\
Transcriptomic feature \\
Gene expression profile class 2 \\
\hline
\end{tabular}

related to smaller tumors, more robust immune response, or fewer genetic mutational events within the melanoma compared with older adults. ${ }^{10,56}$ At 10 years, metastasis in patients aged $11-20$ years is estimated at $10 \%$, for $41-50$ years is $21 \%$, and for $71-80$ years is $30 \% .88$ The COMS study showed no difference in uveal melanoma-related metastasis and death based on gender. However, some reports suggest a better prognosis in females compared with males, with a twofold higher rate of mortality in males compared with females in the first 10 years of posterior uveal melanoma diagnosis. ${ }^{89}$ Hormonal factors, especially estrogen, may cause direct or indirect inhibition of development of metastasis in females.

Tumor size (largest basal diameter and thickness) is one of the most important factors predictive of metastasis and death in patients with uveal melanoma. In a metaanalysis of published reports by Diener-West et al, ${ }^{90}$ the estimated 5-year mortality rates of uveal melanoma was $16 \%$ for small tumors ( $<2$ or $3 \mathrm{~mm}$ tumor thickness and $<10$ or $11 \mathrm{~mm}$ basal diameter), $32 \%$ for medium tumors (3-8 $\mathrm{mm}$ tumor thickness and $<15$ or $16 \mathrm{~mm}$ basal diameter), and $53 \%$ for large tumors ( $>8 \mathrm{~mm}$ tumor thickness and $>15 \mathrm{~mm}$ basal diameter). In a study of 8033 consecutive uveal melanoma patients at a single center with precise data collection, each millimeter increase in tumor thickness was associated with $\sim 5 \%$ increased risk for metastasis at 10 years. ${ }^{2}$ Kaplan-Meier estimates of metastasis at 10 years was $12 \%$ for small melanoma ( $\leq 3 \mathrm{~mm}$ tumor thickness), $26 \%$ for medium melanoma (3.1-8 $\mathrm{mm})$, and $49 \%$ for large melanoma $(>8 \mathrm{~mm}){ }^{2}$

Melanomas arising from or within the ciliary body are more aggressive compared with iris or choroid melanoma. This may be related to the delayed detection of these large tumors, rich blood supply of the ciliary body that increases the risk of hematogenous spread, predilection for monosomy 3 and $8 \mathrm{q}$-gain, and tumor microvascular patterns. ${ }^{87}$ A significant relationship exists between the anatomic site and melanoma-related metastasis, with two to four times higher chance of metastasis in a ciliary body melanoma compared with choroidal melanoma. ${ }^{91}$ The other clinical features with increased melanoma-related metastatic rate include diffuse growth pattern, associated ocular/oculodermal melanocytosis, and extraocular extension.

AJCC classification is an important prognostic factor of posterior uveal melanoma. In a study of 7731 patients with posterior uveal melanoma based on $\mathrm{T}$ category of AJCC classification, the risk for metastasis and death increased twofold with each increasing tumor category, and the 10-year metastatic rate was $15 \%$ for $\mathrm{T} 1,25 \%$ for $\mathrm{T} 2,49 \%$ for $\mathrm{T} 3$, and $63 \%$ for $\mathrm{T} 4$ tumors. ${ }^{92}$

\section{Histopathology features predicting prognosis}

The histopathologic features predicting poor prognosis of uveal melanoma include epithelioid cell type, high mitotic activity, large mean diameter of the 10 largest nucleoli, high microvascular density, presence of microvascular loops and networks, increased tumor-infiltrating lymphocytes and macrophages, and higher expression of insulin-like growth factor 1 receptor, and HLA class I and II antigens. ${ }^{87}$ Currently, most authorities rely on cytogenetic features rather than histopathologic features for prognostication.

\section{Cytogenetic features}

Aberrations in chromosomes 1, 3, 6, and 8 determine the survival in patients with uveal melanoma. The presence of monosomy 3 indicates high-risk melanoma, with an increased risk for metastasis. ${ }^{93}$ Monosomy 3 is associated with higher incidence of clinical and histopathologic risk factors including larger tumor diameter, ciliary body tumor location, extraocular extension, epithelioid cell type, high mitotic rate, and increased vascular loops. The 3-year mortality rate in patients with tumors with monosomy 3 is $50 \%$, and for those with no monosomy 3 is $0 \% .{ }^{93}$ BAP1 has been mapped on chromosome 3 p21.1, 
and identification of BAP1 mutation has strong prognostic value. ${ }^{37,38}$

Chromosome $8 \mathrm{q}$-gain most commonly coexists with monosomy 3 and is more closely associated with poor prognosis than with 8 q-gain alone or monosomy 3 alone. Concomitant loss of chromosomes $1 \mathrm{p}$ and 3 has a stronger correlation with melanoma-related metastasis than either one separately. ${ }^{87}$ Chromosome $6 \mathrm{p}$ gain is usually mutually exclusive with monosomy 3 and is a strong indicator of good prognosis of uveal melanoma, whereas $6 \mathrm{q}$ loss is associated with poor prognosis. ${ }^{87}$

In a study of 500 cases of uveal melanoma, disomy 3 was found in $48 \%$, partial monosomy in $27 \%$, and complete monosomy 3 in $25 \%$ cases. The 3 -year cumulative probability of metastasis was 3\% for disomy $3,5 \%$ for partial monosomy 3 , and $24 \%$ for complete monosomy $3 .{ }^{94} \mathrm{~A}$ multivariate analysis of the joint effects of changes in the six chromosomal regions in 320 uveal melanoma cases revealed increased risk of metastasis with chromosome 3-loss, 1p-loss, 8p-loss, and/or 8q-gain with hazard ratios ranging from 7.90 to $37.25 .{ }^{95}$ Tumors with chromosome 3 disomy/BAP1-WT/EIF1AX-WT have a 10-fold increased risk of metastasis compared with disomy 3/BAP1-WT/EIF1AX mutant tumors. ${ }^{96}$

\section{Transcriptomic features}

Gene expression profiling (GEP) of tumor biopsies may also be used to predict prognosis. ${ }^{97}$ Two classes of uveal melanoma, class 1 and 2 were identified on mRNA analysis by GEP. ${ }^{97}$ Most class 1 tumors are associated with disomy 3 , and chromosome $6 \mathrm{p}$ gain and are considered low-risk tumors. Most, if not all class 2 tumors, however, have monosomy 3 and are considered high-risk tumors with a greater rate of metastasis and melanoma-related mortality. ${ }^{97}$ In a study of 459 patients with uveal melanoma from 12 oncology centers, a strong association was noted between GEP and prognosis of uveal melanoma, with $1 \%$ metastasis in class 1 cases and 26\% metastasis in class 2 cases at a median follow-up of 17 months. ${ }^{98}$ Patients with class 2 tumors tended to be older, and have increased tumor thickness, epithelioid cells, high mitotic rate, and mutations in the BAP1 tumor suppressor gene. For this reason, genetic testing is becoming an important component in diagnosing uveal melanoma and determining prognosis.

\section{The importance of early detection and treatment}

The aforementioned therapies regularly achieve good local disease control. The earlier a melanoma is detected the better the prognosis. ${ }^{99}$ Any pigmented choroidal lesion suspicious of small choroidal melanoma should be assessed for thickness ( $>2 \mathrm{~mm}$ ), subretinal fluid, symptoms (decreased vision, visual field defect, flashes, floaters), orange pigment, margin $\leq 3 \mathrm{~mm}$ from the optic disc, ultrasonographic hollowness, and absence of halo or drusen (TFSOM UHHD) 35,36 (Figure 4). Choroidal nevus with any of the one factor of TFSOM UHHD have a 38\% chance and those with two or more factors have over $50 \%$ chance for transformation into melanoma at 5 years. ${ }^{35,36}$ The most dangerous combination of factors with $69 \%$ risk for growth include thickness $>2 \mathrm{~mm}$, symptoms, and tumor margin near the disc. ${ }^{35,36}$ An asymptomatic choroidal nevus with thickness $<2 \mathrm{~mm}$ displaying signs of chronicity such as drusen, RPE atrophy, RPE hyperplasia, RPE detachment, and RPE fibrous metaplasia, with/without surrounding halo, and with no overlying orange pigment or subretinal fluid is considered as a 'low-risk choroidal nevus' with minimal chance of transformation into melanoma. A choroidal nevus with one or more risk factors (greater thickness (>2 mm), subretinal fluid, symptoms, orange pigment, margin near disc, ultrasonographic hollowness, and absence of halo or drusen) is a 'high-risk choroidal nevus' with a greater chance of transformation into melanoma. Those tumors with two or more risk factors probably represent small choroidal melanoma and early treatment is indicated. ${ }^{35,36}$

The most important clinical predictor of metastasis remains cytogenetics and tumor size. ${ }^{2,94-98}$ With an assumption of constant growth rate of metastases, Eskelin et al ${ }^{100}$ estimated that micrometastases from uveal melanoma could develop as early as 5 years before the treatment of the primary tumor. At this estimated time of micrometastases, the theoretically estimated size of the primary tumor would be $\sim 3 \mathrm{~mm}$ in diameter and $1.5 \mathrm{~mm}$ in height or only $7 \mathrm{~mm}^{3}$ in volume. ${ }^{100}$ This underscores the importance of early diagnosis of uveal melanoma and possible benefit of adjuvant systemic chemotherapy in patients with uveal melanoma at the time of initial diagnosis. As in many other cancer indications, both early detection and early treatment (Figure 4) may be critical for a positive long-term survival outcome in uveal melanoma. Taken together, these observations call attention to an unmet medical need for the early treatment of small melanocytic lesions or small melanomas in the eye to achieve local disease control and vision preservation.

The combination of early detection, gene expression profiling, and vision-sparing treatments have the potential to help patients earlier in the treatment process before their tumors are capable of metastasis. More research in these areas could provide a great benefit for patients in the near future. 


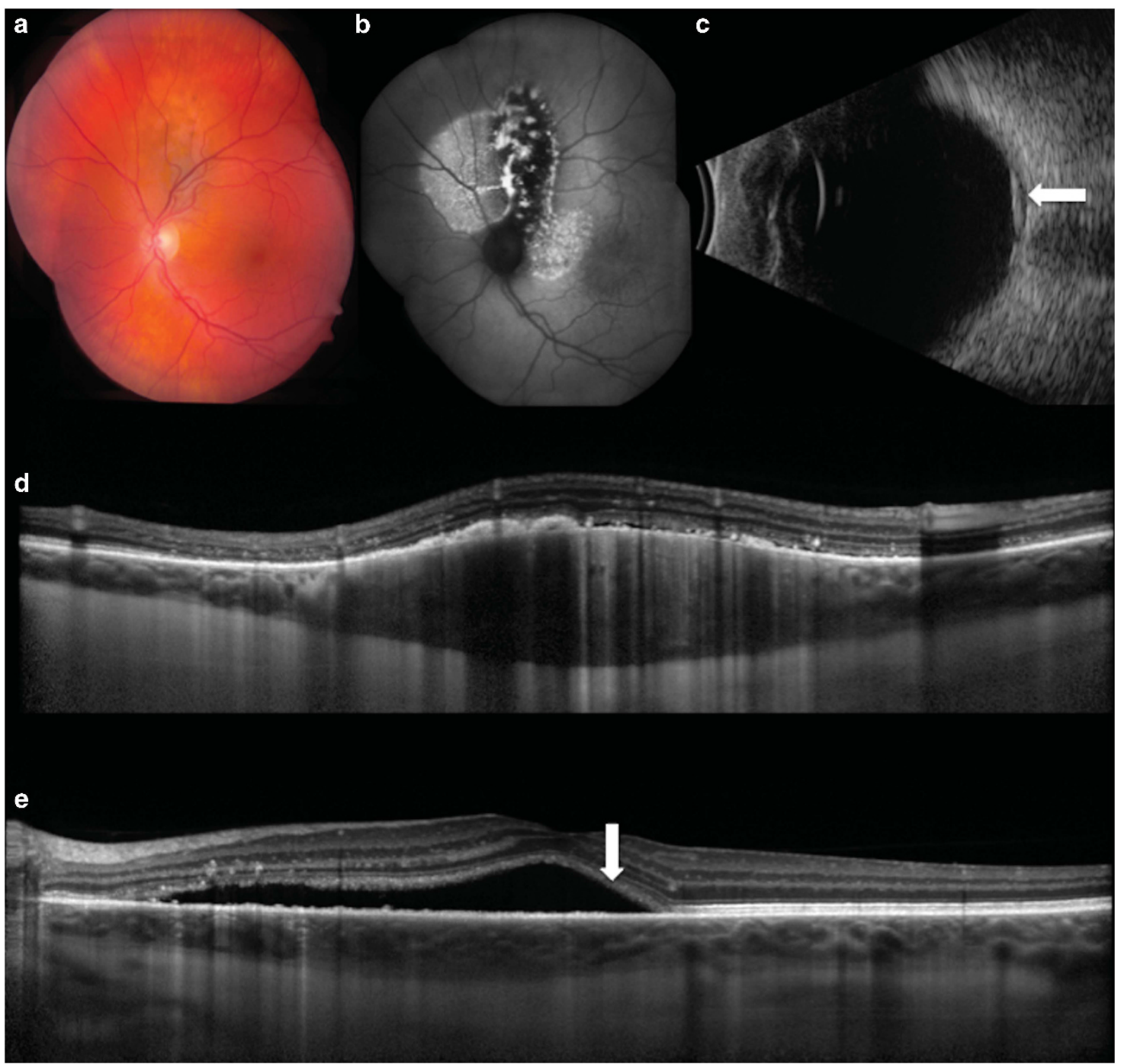

Figure 4 Small choroidal melanoma with all eight risk factors TFSOM UHHD (tumor thickness $>2 \mathrm{~mm}$, subretinal fluid, symptoms, orange pigment, margin near disc, ultrasonographic hollowness, and absence of halo or drusen). (a) Fundus photograph showing peripapillary small choroidal melanoma above the optic disc. (b) Fundus autofluorescence demonstrating bright hyperautofluorescence due to lipofuscin pigment within the tumor and surrounding hyperautofluorescence due to subretinal fluid. (c) B-scan USG showing a 2.3-mm-thick choroidal lesion with acoustic hollowing and choroidal excavation (white arrow). (d) EDI-OCT showing choroidal thickening with compression of overlying choriocapillaries. (e) EDI-OCT showing subretinal fluid and shaggy photoreceptors (white arrow) in the fovea and perifoveal region.

\section{Conclusion}

This review of ocular melanoma provides comprehensive analyses including risk factors, diagnosis, and treatment (existing and newer methods) of this rare and important disease, uveal melanoma. With moderately high mortality rates, there is clearly an unmet need for these patients, and newer treatments should be explored to control melanoma before it demonstrates capacity to spread. Early detection using published risk factors ${ }^{35,36}$ and established or newer treatments, especially with targeted therapy at an earlier point in tumor development, could offer greater patient benefit.

\section{Conflict of interest}

The authors declare no conflict of interest.

\section{Acknowledgements}

Amy Cohen, MS and Elisabet de los Pinos, PhD (Aura Biosciences Inc., Cambridge, MA, USA). Carol L Shields serves on the Science Advisory Board of Aura Biosciences, 
Cambridge, MA, USA. This work was supported by The Operation Eyesight Universal Institute for Eye Cancer (SK), Hyderabad Eye Research Foundation, Hyderabad, India (SK), and Eye Tumor Research Foundation, Philadelphia, Pennsylvania (CLS).

\section{References}

1 Chang AE, Karnell LH, Menck HR. The National Cancer Data Base report on cutaneous and noncutaneous melanoma: a summary of 84,836 cases from the past decade. The American College of Surgeons Commission on Cancer and the American Cancer Society. Cancer 1998; 83(8): 1664-1678.

2 Shields CL, Furuta M, Thangappan A, Nagori S, Mashayekhi A, Lally DR et al. Metastasis of uveal melanoma millimeter-by-millimeter in 8033 consecutive eyes. Arch Ophthalmol 2009; 127(8): 989-998.

3 Singh AD, Turell ME, Topham AK. Uveal melanoma: trends in incidence, treatment, and survival. Ophthalmology 2011; 118(9): 1881-1885.

4 Virgili G, Gatta G, Ciccolallo L, Capocaccia R, Biggeri A, EUROCARE Working Group et al. Incidence of uveal melanoma in Europe. Ophthalmology 2007; 114: 2309-2315.

5 Kivelä T. The epidemiological challenge of the most frequent eye cancer: retinoblastoma, an issue of birth and death. Br J Ophthalmol 2009; 93(9): 1129-1131.

6 Park SJ, Oh CM, Kim BW, Woo SJ, Cho H, Park KH. Nationwide Incidence of Ocular Melanoma in South Korea by using the National Cancer Registry Database (1999-2011). Invest Ophthalmol Vis Sci 2015; 56(8): 4719-4724.

7 Stang A, Parkin DM, Ferlay J, Jöckel KH. International uveal melanoma incidence trends in view of a decreasing proportion of morphological verification. Int J Cancer 2005; 114(1): 114-123.

8 Andreoli MT, Mieler WF, Leiderman YI. Epidemiological trends in uveal melanoma. Br J Ophthalmol 2015; 99(11): 1550-1553.

9 Singh AD, Topham A. Incidence of uveal melanoma in the United States: 1973-1997. Ophthalmology 2003; 110(5): 956-961.

10 Shields CL, Kaliki S, Arepalli S, Atalay HT, Manjandavida FP, Pieretti G et al. Uveal melanoma in children and teenagers. Saudi J Ophthalmol 2013; 27(3): 197-201.

11 Singh AD, Schoenfield LA, Bastian BC, Aziz HA, Marino MJ, Biscotti CV. Congenital uveal melanoma? Surv Ophthalmol 2016; 61(1): 59-64.

12 Biswas J, Kabra S, Krishnakumar S, Shanmugam MP. Clinical and histopathological characteristics of uveal melanoma in Asian Indians. A study of 103 patients. Indian J Ophthalmol 2004; 52(1): 41-44.

13 Cheng CY, Hsu WM. Incidence of eye cancer in Taiwan: an 18-year review. Eye (Lond) 2004; 18(2): 152-158.

14 Liu YM, Li Y, Wei WB, Xu X, Jonas JB. Clinical characteristics of 582 patients with uveal melanoma in China. PLoS One 2015; 10 (12): e0144562.

15 Sakamoto T, Sakamoto M, Yoshikawa H, Hata Y, Ishibashi T, Ohnishi $\mathrm{Y}$ et al. Histologic findings and prognosis of uveal malignant melanoma in Japanese patients. Am J Ophthalmol 1996; 121(3): 276-283.

16 Phillpotts BA, Sanders RJ, Shields JA, Griffiths JD, Augsburger JA, Shields CL. Uveal melanomas in black patients: a case series and comparative review. J Natl Med Assoc 1995; 87(9): 709-714.

17 Hudson HL, Valluri S, Rao NA. Choroidal melanomas in Hispanic patients. Am J Ophthalmol 1994; 118(1): 57-62.

18 Vajdic CM, Kricker A, Giblin M, McKenzie J, Aitken J, Giles GG et al. Incidence of ocular melanoma in Australia from 1990 to 1998. Int J Cancer 2003; 105 (1):117-122.

19 Shields CL, Kaliki S, Cohen MN, Shields PW, Furuta M, Shields JA. Prognosis of uveal melanoma based on race in 8100 patients: The 2015 Doyne Lecture. Eye (Lond) 2015; 29 (8): 1027-1035.

20 Margo CE, Mulla Z, Billiris K. Incidence of surgically treated uveal melanoma by race and ethnicity. Ophthalmology 1998; 105(6): 1087-1090.

$21 \mathrm{Hu}$ DN, Yu GP, McCormick SA, Schneider S, Finger PT. Population-based incidence of uveal melanoma in various races and ethnic groups. Am J Ophthalmol 2005; 140(4): 612-617.

22 Weis E, Shah CP, Lajous M, Shields JA, Shields CL. The association between host susceptibility factors and uveal melanoma: a meta-analysis. Arch Ophthalmol 2006; 124(1): 54-60.

23 Gonder JR, Ezell PC, Shields JA, Augsburger JJ. Ocular melanocytosis. A study to determine the prevalence rate of ocular melanocytosis. Ophthalmology 1982; 89: 950-952.

24 Singh AD, De Potter P, Fijal BA, Shields CL, Shields JA, Elston RC. Lifetime prevalence of uveal melanoma in white patients with oculo(dermal) melanocytosis. Ophthalmology 1998; 105: 195-198.

25 Shields CL, Kaliki S, Livesey M, Walker B, Garoon R, Bucci $\mathrm{M}$ et al. Association of ocular and oculodermal melanocytosis with the rate of uveal melanoma metastasis: analysis of 7872 consecutive eyes. JAMA Ophthalmol 2013; 131(8): 993-1003.

26 Bataille V, Sasieni P, Cuzick J, Hungerford JL, Swerdlow A, Bishop JA. Risk of ocular melanoma in relation to cutaneous and iris naevi. Int J Cancer 1995; 60(5): 622-626.

27 Hammer H, Oláh J, Tóth-Molnár E. Dysplastic nevi are a risk factor for uveal melanoma. Eur J Ophthalmol 1996; 6(4): 472-474.

28 Weis E, Shah CP, Lajous M, Shields JA, Shields CL. The association of cutaneous and iris nevi with uveal melanoma: a meta-analysis. Ophthalmology 2009; 116: 536-543.

29 Territo C, Shields CL, Shields JA, Augsburger JJ, Schroeder RP. Natural course of melanocytic tumors of the iris. Ophthalmology 1988; 95: 1251-1255.

30 Shields CL, Kaliki S, Hutchinson A, Nickerson S, Patel J, Kancherla $S$ et al. Iris nevus growth into melanoma: analysis of 1611 consecutive eyes: the ABCDEF guide. Ophthalmology 2013; 120(4): 766-772.

31 Qiu M, Shields CL. Choroidal nevus in the United States adult population: racial disparities and associated factors in the National Health and Nutrition Examination Survey. Ophthalmology 2015; 122(10): 2071-2083.

32 Sieburth RM, Qiu M, Shields CL. Sex differences in the relationship between obesity and choroidal nevus in US adults. Invest Ophthalmol Vis Sci 2015; 56(12): 7489-7495.

33 Qiu M, Shields CL. Relationship between female reproductive factors and choroidal nevus in US women: analysis of data from the 2005-2008 National Health and Nutrition Examination Survey. JAMA Ophthalmol 2015; 133 (11): 1287-1294.

34 Singh AD, Kalyani P, Topham A. Estimating the risk of malignant transformation of a choroidal nevus. Ophthalmology 2005; 112(10): 1784-1789. 
35 Shields CL, Cater J, Shields JA, Singh AD, Santos MC, Carvalho C. Combination of clinical factors predictive of growth of small choroidal melanocytic tumors. Arch Ophthalmol 2000; 118(3): 360-364.

36 Shields CL, Furuta M, Berman EL, Zahler JD, Hoberman DM, Dinh DH et al. Choroidal nevus transformation into melanoma: analysis of 2514 consecutive cases. Arch Ophthalmol 2009; 127(8): 981-987.

37 Carbone M, Yang H, Pass HI, Krausz T, Testa JR, Gaudino G. BAP1 and cancer. Nat Rev Cancer 2013; 13(3): 153-159.

38 Gupta MP, Lane AM, DeAngelis MM, Mayne K, Crabtree M, Gragoudas ES et al. Clinical characteristics of uveal melanoma in patients with germline BAP1 mutations. JAMA Ophthalmol 2015; 133(8): 881-887.

39 Shah CP, Weis E, Lajous M, Shields JA, Shields CL. Intermittent and chronic ultraviolet light exposure and uveal melanoma: a meta-analysis. Ophthalmology 2005; 112(9): 1599-1607.

40 Schmidt-Pokrzywniak A, Jöckel KH, Bornfeld N, Sauerwein W, Stang A. Positive interaction between light iris color and ultraviolet radiation in relation to the risk of uveal melanoma: a case-control study. Ophthalmology 2009; 116(2): 340-348.

41 Gué nel P, Laforest L, Cyr D, Févotte J, Sabroe S, Dufour C et al. Occupational risk factors, ultraviolet radiation, and ocular melanoma: a case-control study in France. Cancer Causes Control 2001; 12: 451-459.

42 Holly EA, Aston DA, Ahn DK, Smith AH. Intraocular melanoma linked to occupations and chemical exposures. Epidemiology 1996; 7: 55-61.

43 Fernandes BF, Marshall JC, Burnier MN Jr. Blue light exposure and uveal melanoma. Ophthalmology 2006; 113(6): 1062.

44 Ge YR, Tian N, Lu Y, Wu Y, Hu QR, Huang ZP. Occupational cooking and risk of uveal melanoma: a meta-analysis. Asian Pac J Cancer Prev 2012; 13(10): 4927-4930.

45 Shields JA, Shields CL. Intraocular Tumors. An Atlas and Textbook, 2nd edn. Lippincott Williams and Wilkins: Philadelphia, PA, USA, 2008, pp 85-139.

46 Henderson E, Margo CE. Iris melanoma. Arch Pathol Lab Med 2008; 132(2): 268-272.

47 Shields CL, Kaliki S, Shah S, Luo W, Furuta M, Shields JA. Iris melanoma features and prognosis in children and adults in 317 patients. The 2011 Leonard Apt Lecture. J AAPOS 2012; 16: 10-16.

48 Shields CL, Shields JA, Shields MB, Augsburger J. Prevalence and mechanisms of secondary intraocular pressure elevation in eyes with intraocular tumors. Ophthalmology 1987; 94: 839-846.

49 Demirci H, Shields CL, Shields JA, Eagle Jr RC, Honavar SG. Diffuse iris melanoma: a report of 25 cases. Ophthalmology 2002; 109(8): 1553-1560.

50 Demirci H, Shields CL, Shields JA, Eagle Jr RC, Honavar S. Ring melanoma of the anterior chamber angle: a report of fourteen cases. Am J Ophthalmol 2001; 132(3): 336-342.

51 Edge SB, Byrd DR, Compton CC, Fritz AG, Greene FL, Trotti A et al. (eds). Malignant melanoma of the uvea. In: AJCC Cancer Staging Manual, 7th edn. Springer: New York, NY, USA, 2010, pp 547-559.

52 Bianciotto CG, Shields CL, Romanelli M, Romanelli-Gobbi M, Mazzuca Jr D, Green WR et al. Assessment of anterior segment tumors with ultrasound biomicroscopy versus anterior segment optical coherence tomography in 200 cases. Ophthalmology 2011; 118(7): 1297-1302.
53 Shields CL, Manquez ME, Ehya H, Mashayekhi A, Danzig CJ, Shields JA. Fine-needle aspiration biopsy of iris tumors in 100 consecutive cases: technique and complications. Ophthalmology 2006; 113(11): 2080-2086.

54 Rahmi A, Mammar H, Thariat J, Angellier G, Herault J, Chauvel $\mathrm{P}$ et al. Proton beam radiotherapy for presumed and confirmed iris melanomas: a review of 36 cases. Graefes Arch Clin Exp Ophthalmol 2014; 252(9): 1515-1521.

55 Shields CL, Shah SU, Bianciotto CG, Emrich J, Komarnicky L, Shields JA. Iris melanoma management with iodine- 125 plaque radiotherapy in 144 patients: impact of melanoma-related glaucoma on outcomes. Ophthalmology 2013; 120(1): 55-61.

56 Kaliki S, Shields CL, Mashayekhi A, Ganesh A, Furuta M, Shields JA. Influence of age on prognosis of young patients with uveal melanoma: a matched retrospective cohort study. Eur J Ophthalmol 2013; 23(2): 208-216.

57 Shields CL, Shields JA, Materin M, Gershenbaum E, Singh AD, Smith A. Iris melanoma: risk factors for metastasis in 169 consecutive patients. Ophthalmology 2001; 108(1): 172-178.

58 Damato EM, Damato BE. Detection and time to treatment of uveal melanoma in the United Kingdom: an evaluation of 2,384 patients. Ophthalmology 2012; 119(8): 1582-1589.

59 Demirci H, Shields CL, Shields JA, Honavar SG, Eagle RC Jr. Ring melanoma of the ciliary body: report on twentythree patients. Retina 2002; 22(6): 698-706.

60 Shields CL, Kaliki S, Rojanaporn D, Ferenczy SR, Shields JA. Enhanced depth imaging optical coherence tomography of small choroidal melanoma: comparison with choroidal nevus. Arch Ophthalmol 2012; 130(7): 850-856.

61 Fuller DG, Snyder WB, Hutton WL, Vaiser A. Ultrasonographic features of choroidal malignant melanomas. Arch Ophthalmol 1979; 97: 1465-1472.

62 Ossoinig KC. Standardized echography: basic principles, clinical applications, and results. Int Ophthalmol Clin 1979; 19(4): 127-210.

63 Pettit TH, Barton A, Foos RY, Christensen RE. Fluorescein angiography of choroidal melanomas. Arch Ophthalmol 1970; 83(1): 27-38.

64 Augsburger JJ, Golden MI, Shields JA. Fluorescein angiography of choroidal malignant melanomas with retinal invasion. Retina 1984; 4(4): 232-241.

65 Shields CL, Shields JA, De Potter P. Patterns of indocyanine green videoangiography of choroidal tumours. Br J Ophthalmol 1995; 79(3): 237-245.

66 Shields JA, Mashayekhi A, Ra S, Shields CL. Pseudomelanomas of the posterior uveal tract: the 2006 Taylor R. Smith Lecture. Retina 2005; 25(6): 767-771.

67 Logan PT, Aldrees S, Qutub MF, Vila N, Bravo-Filho V, Burnier MN. Evaluating the in vivo efficacy of a novel first in class drug for the treatment of primary uveal melanoma. Presentation at ARVO Annual Meeting; June 2015, Denver, $\mathrm{CO}, \mathrm{USA}$

68 Shields CL, Shields JA, Perez N, Singh AD, Cater J. Primary transpupillary thermotherapy for choroidal melanoma in 256 consecutive cases. Outcomes and limitations. Ophthalmology 2002; 109(2): 225-234.

69 Mashayekhi A, Shields CL, Rishi P, Atalay HT, Pellegrini M, McLaughlin JP et al. Primary transpupillary thermotherapy for choroidal melanoma in 391 cases: importance of risk factors in tumor control. Ophthalmology 2015; 122(3): 600-609. 
70 Cerman E, Çekiç O. Clinical use of photodynamic therapy in ocular tumors. Surv Ophthalmol 2015; 60(6): 557-574.

71 Collaborative Ocular Melanoma Study Group. The COMS randomized trial of iodine 125 brachytherapy for choroidal melanoma: V. Twelve-year mortality rates and prognostic factors: COMS report No. 28. Arch Ophthalmol 2006; 124(12): 1684-1693.

72 Hawkins BS, Collaborative Ocular Melanoma Study Group. The Collaborative Ocular Melanoma Study (COMS) randomized trial of pre-enucleation radiation of large choroidal melanoma: IV. Ten-year mortality findings and prognostic factors. COMS report number 24. Am J Ophthalmol 2004; 138(6): 936-951.

73 Shields CL, Cater J, Shields JA, Chao A, Krema H, Materin M et al. Combined plaque radiotherapy and transpupillary thermotherapy for choroidal melanoma in 270 consecutive patients. Arch Ophthalmol 2002; 120: 933-940.

74 Gunduz K, Shields CL, Shields JA, Cater J, Freire J, Brady LW. Radiation retinopathy following plaque radiotherapy of posterior uveal melanoma. Arch Ophthalmol 1999; 117(5): 609-614.

75 Kaliki S, Shields CL, Rojanaporn D, Badal J, Devisetty L, Emrich $\mathrm{J}$ et al. Scleral necrosis after plaque radiotherapy of uveal melanoma: a case-control study. Ophthalmology 2013; 120(5): 1004-1011.

76 Gragoudas ES. Proton beam irradiation of uveal melanomas: the first 30 years. The Weisenfeld Lecture. Invest Ophthalmol Vis Sci 2006; 47(11): 4666-4673.

77 Dunavoelgyi R, Dieckmann K, Gleiss A, Sacu S, Kircher K, Georgopoulos $\mathrm{M}$ et al. Local tumor control, visual acuity, and survival after hypofractionated stereotactic photon radiotherapy of choroidal melanoma in 212 patients treated between 1997 and 2007. Int J Radiat Oncol Biol Phys 2011; 81 (1): 199-205.

78 Damato B. The role of eyewall resection in uveal melanoma management. Int Ophthalmol Clin 2006; 46(1): 81-93.

79 Konstantinidis L, Groenewald C, Coupland SE, Damato B. Long-term outcome of primary endoresection of choroidal melanoma. Br J Ophthalmol 2014; 98(1): 82-85.

80 Shields JA, Shields CL. Management of posterior uveal melanoma: past, present, and future: the 2014 Charles L. Schepens lecture. Ophthalmology 2015; 122(2): 414-428.

81 Singh AD, Rennie IG, Kivela T, Seregard S, Grossniklaus H. The Zimmerman-McLean-Foster hypothesis: 25 years later. Br J Ophthalmol 2004; 88(7): 962-967.

82 Grimm J, Scheinberg DA. Will nanotechnology influence targeted cancer therapy? Semin Radiat Oncol 2011; 21: 80-87.

83 Mitsunaga M, Nakajima T, Sano K, Kramer-Marek G, Choyke PL, Kobayashi H. Immediate in vivo target-specific cancer cell death after near infrared photoimmunotherapy. BMC Cancer 2012; 12: 345.

84 Schuler-Thurner B, Bartz-Schmidt KU, Bornfeld N, Cursiefen C, Fuisting B, Grisanti S et al. Immunotherapy of uveal melanoma: vaccination against cancer. Multicenter adjuvant phase 3 vaccination study using dendritic cells laden with tumor RNA for large newly diagnosed uveal melanoma. Ophthalmologe 2015; 112(12): 1017-1021.

85 Diener-West M, Reynolds SM, Agugliaro DJ, Caldwell R, Cumming K, Earlees JD et al. Development of metastatic disease after enrollment in the COMS trials for treatment of choroidal melanoma: Collaborative Ocular Melanoma
Study Group Report No. 26. Arch Ophthalmol 2005; 123: 1639-1643.

86 Kujala E, Mäkitie T, Kivelä T. Very long-term prognosis of patients with malignant uveal melanoma. Invest Ophthalmol Vis Sci 2003; 44(11): 4651-4659.

87 Kaliki S, Shields CL, Shields JA. Uveal melanoma: estimating prognosis. Indian J Ophthalmol 2015; 63(2): 93-102.

88 Shields CL, Kaliki S, Furuta M, Mashayekhi A, Shields JA. Clinical spectrum and life prognosis of patients with uveal melanoma based on age at presentation in 8033 cases. Retina 2012; 32: 1363-1372.

89 Zloto O, Pe'er J, Frenkel S. Gender differences in clinical presentation and prognosis of uveal melanoma. Invest Ophthalmol Vis Sci 2013; 54: 652-656.

90 Diener-West M, Hawkins BS, Markowitz JA, Schachat AP. A review of mortality from choroidal melanoma. II. A meta-analysis of 5-year mortality rates following enucleation, 1966 through 1988. Arch Ophthalmol 1992; 110: 245-250.

91 Li W, Gragoudas ES, Egan KM. Metastatic melanoma death rates by anatomic site after proton beam irradiation for uveal melanoma. Arch Ophthalmol 2000; 118(8): 1066-1070.

92 Shields CL, Kaliki S, Furuta M, Fulco E, Alarcon C, Shields JA. American Joint Committee on Cancer classification of posterior uveal melanoma (tumor size category) predicts prognosis in 7731 patients. Ophthalmology 2013; 120: 2066-2071.

93 Prescher G, Bornfeld N, Hirche H, Horsthemke B, Jöckel KH, Becher R. Prognostic implications of monosomy 3 in uveal melanoma. Lancet 1996; 347: 1222-1225.

94 Shields CL, Ganguly A, Bianciotto CG, Turaka K, Tavallali A, Shields JA. Prognosis of uveal melanoma in 500 cases using genetic testing of fine-needle aspiration biopsy specimens. Ophthalmology 2011; 118(2): 396-401.

95 Ewens KG, Kanetsky PA, Richards-Yutz J, Al-Dahmash S, De Luca MC, Bianciotto CG et al. Genomic profile of 320 uveal melanoma cases: chromosome $8 \mathrm{p}$-loss and metastatic outcome. Invest Ophthalmol Vis Sci 2013; 54(8): 5721-5729.

96 Ewens KG, Kanetsky PA, Richards-Yutz J, Purrazzella J, Shields CL, Ganguly T et al. Chromosome 3 status combined with BAP1 and EIF1AX mutation profiles are associated with metastasis in uveal melanoma. Invest Ophthalmol Vis Sci 2014; 55(8): 5160-5167.

97 Field MG, Harbour JW. Recent developments in prognostic and predictive testing in uveal melanoma. Curr Opin Ophthalmol 2014; 25(3): 234-239.

98 Onken MD, Worley LA, Char DH, Augsburger JJ, Correa ZM, Nudleman E et al. Collaborative Ocular Oncology Group report number 1: prospective validation of a multi-gene prognostic assay in uveal melanoma. Ophthalmology 2012; 119: $1596-1603$.

99 Damato B. Progress in the management of patients with uveal melanoma. The 2012 Ashton Lecture. Eye (Lond) 2012; 26 (9):1157-1172.

100 Eskelin S, Pyrhönen S, Summanen P, Hahka-Kemppinen M, Kivelä T. Tumor doubling times in metastatic malignant melanoma of the uvea: tumor progression before and after treatment. Ophthalmology 2000; 107(8): 1443-1449.

101 Collaborative Ocular Melanoma Study Group. Factors predictive of growth and treatment of small choroidal melanoma: COMS Report No. 5. Arch Ophthalmol 1997; 115: 1537-1544. 